\title{
A EVOLUÇÃO BIOLÓGICA À LUZ DA CULTURA CIENTÍFICA E HISTÓRIA DA CIÊNCIA EM LIVROS DIDÁTICOS DO ENSINO MÉDIO (PNLD, 2015)
}

\author{
Beatriz Marques Assad ${ }^{1}$ \\ Rebekah Giese de Paula Machado ${ }^{2}$ \\ Evander Ruthieri Saturno da Silva ${ }^{3}$
}

\begin{abstract}
RESUMO
O estudo da evolução biológica é considerado um dos principais eixos que unificam os conhecimentos no ensino de Ciências e Biologia. No cenário mundial, porém, o ensino desta temática enfrenta diversos desafios. O livro didático, na educação básica brasileira, é um dos principais, senão o único, material pedagógico utilizado. Deste modo, foram selecionados como objeto de estudo deste texto os três livros didáticos de Biologia com os maiores índices de distribuição no território nacional (PNLD, 2015), nos quais analisou-se o conteúdo de evolução biológica quanto à presença de elementos caracterizados como História da Ciência e de cultura científica. As três obras didáticas incluíram o conteúdo esperado conforme os parâmetros da DCNEM e BNCC, e divergiram quanto à visibilidade de determinados temas. Além disso, todos os livros apresentaram elementos de História da Ciência e cultura científica. Poderiam, contudo, estar mais bem desenvolvidos ao longo dos textos principais, posto que a ocorrência de cultura científica se deu majoritariamente nos conteúdos compreendidos em sessões extras do livro. Conclui-se, portanto, que os três livros são recursos didáticos adequados para auxiliar o professor no ensino de evolução biológica, porém insuficientes para obtenção de uma visão crítica da ciência.
\end{abstract}

Palavras-chave: análise de conteúdo; ensino de biologia; livro didático.

\author{
BIOLOGICAL EVOLUTION IN THE LIGHT OF SCIENTIFIC CULTURE \\ AND HISTORY OF SCIENCE IN HIGH SCHOOL TEXTBOOKS (PNLD, 2015)
}

\begin{abstract}
The study of biological evolution is considered to be one of the main axes that unify the knowledges in the teaching of Science and Biology. However, in the world scenario the teaching of this thematic faces some challenges. The textbook, in the Brazilian basic education, is one of the main, if not the only, pedagogic material used. This way, were selected as object of study for this work the three textbooks with the higher distribution rates in the national territory (PNLD, 2015), in which was analyzed the content of biological evolution in terms of the presence of elements characterized as History of Science and scientific culture. The three didactic materials included the expected content, according to the PCNEM and BNCC parameters and diverged about the visibility of certain themes. Besides, all the books presented elements of History of Science and scientific culture. But they could be better developed along the main texts, since the occurrence of scientific culture was given mostly in the extra sections of the books. Therefore, it was concluded that the three books are appropriate didactic resources to assist the teachers in the teaching of biological evolution, however, insufficient to achieve a critical vision of Science.
\end{abstract}

Keywords: content analysis; biology teaching; textbook.

Recebido em: 6/5/2020

Aceito em: $14 / 5 / 2020$

\footnotetext{
1 Autora correspondente. Universidade Federal da Integração Latino-Americana - Unila. Av. Silvio Américo Sasdelli, 1842 - Vila A. Foz do Iguaçu/PR, Brasil. CEP 85866-000. http://lattes.cnpq.br/8391845938071235. https://orcid.org/0000-0002-3672-1876. bia.assad95@gmail.com

2 Universidade Federal da Integração Latino-Americana - Unila. Foz do Iguaçu/PR, Brasil. http://lattes.cnpq.br/5274621673430628. https:// orcid.org/0000-0002-8982-2128.

3 Universidade Federal da Integração Latino-Americana - Unila. Foz do Iguaçu/PR, Brasil. http://lattes.cnpq.br/1809837136738718. https:// orcid.org/0000-0002-5988-3739.
} 


\section{INTRODUÇÃO}

O pensamento evolutivo, para grande parte da comunidade científica, é o eixo central e unificador das Ciências Biológicas (DOBZHANSKY, 1973; FUTUYMA, 2009). Os conceitos proporcionados pelo pensamento evolutivo trazem significados a uma enorme quantidade de conhecimentos, sendo uma teoria de poder e estímulo intelectual, a qual nos permite compreender como os organismos que conhecemos, aparentemente muito diferentes entre si, possuem unidade quanto à organização celular e código genético (RIDLEY, 2006).

A Evolução Biológica também é apontada pelas Diretrizes Curriculares Nacionais para Ensino Médio - DCNEM - (BRASIL, 2013), como eixo integrador dos conteúdos biológicos, considerado um dos conceitos mais influentes do pensamento ocidental. Ademais, o tema é destacado pela Base Nacional Comum Curricular - BNCC - (BRASIL, 2018) como uma das principais competências dentro da área de "Ciências da Natureza e suas Tecnologias". Estes documentos curriculares citam que os estudantes devem ser capazes de compreender as ciências como construções humanas - cujo processo de construção sofre rupturas, estabelecimento e quebra de paradigmas - e como isso se relaciona com a transformação da sociedade. Ainda, segundo a BNCC, o ensino deve possibilitar que os estudantes "explorem os diferentes modos de pensar e de falar da cultura científica, situando-a como uma das formas de organização do conhecimento produzido em diferentes contextos históricos e sociais, possibilitando-Ihes apropriar-se dessas linguagens específicas" (BRASIL, 2018, p. 537).

Dessa maneira, compreender os processos evolutivos e seu caráter dentro da História da Ciência deve ser parte significativa nas formações intelectuais, incorporando contextos sociais e éticos, essenciais para a construção do pensamento do processo científico (MATTHEWS, 1995), afinal "o estudo histórico de como um cientista realmente desenvolveu sua pesquisa ensina mais sobre o processo científico do que qualquer manual de metodologia científica" (MARTINS, 2006, p. 23).

O conteúdo direcionado à evolução, porém, nem sempre é tratado de forma satisfatória dentro do ambiente escolar, tanto no cenário da educação nacional quanto internacional, sendo destacados como possíveis desafios do ensino de evolução o ensino de evolução como caráter isolado das outras áreas de conhecimento, as concepções prévias dos estudantes, muitas vezes fortemente ligadas à aspectos religiosos, concepções inadequadas sobre a natureza controversa do tema, entre outros (BORGERDING et al., 2015; PEREIRA; EL-HANI, 2011; SINATRA et al., 2008; TIDON; LEWONTIN, 2004).

De acordo com os diagnósticos coligidos por alguns especialistas, a fragmentação e a omissão no estudo de evolução é uma situação preocupante, em especial porque pesquisas mostram que a teoria evolutiva tem baixos índices de compreensão e pouca credibilidade fora do meio acadêmico (GOEDERT; DELIZOICOV; ROSA, 2003; PIOLLI; DIAS, 2004). No Brasil, o tema evolução geralmente é lecionado de forma concentrada no final do 3ㅇan ano do Ensino Médio, e os conteúdos relacionados à evolução normalmente estão localizados ao final dos livros didáticos, muitas vezes sendo suprimidos das aulas de biologia (ALMEIDA; ROCHA FALCÃO, 2010; TIDON; LEWONTIN, 2004). 
O livro didático - LD - nas instituições de Educação Básica brasileira é um importante aliado para o ensino-aprendizagem em Ciências Biológicas. O LD é, muitas vezes, o único recurso didático usado pelos professores na escola (JUNIOR; ANDRADE, 2015). Sua importância é indiscutivel no cenário da educação e da cultura escolar, e pode ser compreendida em termos históricos por meio da relação entre este material educativo, as políticas públicas para a educação e as práticas constitutivas do ensino escolar. Esta importância é atestada, entre outros fatores, pelo debate em torno da sua função na democratização de saberes socialmente legitimados e relacionados a diferentes campos de conhecimento, pela polêmica acerca do seu papel como estruturador da atividade docente e pelos investimentos de governos em programas de avaliação (MARTINS, 2016). Além disso, "os livros de Ciências têm uma função que os difere dos demais - a aplicação do método científico, estimulando a análise de fenômenos, o teste de hipóteses e a formulação de conclusões" (VASCONCELO; SOUTO, 2003, p. 93). Quanto a isso, o Ministério da Educação - MEC - estabelece que os LDs de biologia para o Ensino Médio devem conter elementos de cultura científica, garantindo adequada alfabetização científico-tecnológica associada a aspectos socioculturais, políticos e econômicos, mas sem atentarem a História da Ciência (MEC, 2013).

É comum a abordagem do tema "Evolução" nos LDs desprovido de contextualização histórica para a compreensão, por parte dos alunos, de como os conceitos foram desenvolvidos ao longo do tempo ou, ainda, o assunto é tratado como concluído, remetendo à ciência como algo absoluto (ALMEIDA; ROCHA FALCÃO, 2010). Esse impasse também é observado em outras áreas que tratam do conhecimento científico, tal como nos livros didáticos destinados ao ensino de química (VIDAL; PORTO, 2012).

Para Batista (2007), é consensual que tanto a história quanto a filosofia da ciência trazem inúmeros benefícios que facilitam o processo de ensino-aprendizagem, tanto para os alunos quanto para os professores. Atuam de forma interdisciplinar e conduzem a ideias inovadoras e a uma diferente visão de mundo e da cultura científica, validando a relação cultura-intelectualidade (BATISTA, 2007).

Tendo em vista esses fatores e que a "essência da ciência é o processo de solução de problemas na busca de um entendimento do nosso mundo, uma história da ciência é antes de tudo uma história dos problemas da ciência e de sua solução, ou de soluções tentadas" (MAYR, 1998, p. 15). Enfatizando principalmente a solução dos problemas, é necessário apresentar, também, a história sobre as tentativas malsucedidas (MAYR, 1998). Leite (2004) hipotetiza que "professores não fazem uso da História da Ciência porque não a conhecem, por terem pouco ou nenhum contato com ela durante a sua formação". Dessa forma, materiais de apoio ao docente, tal como os livros didáticos, possibilitam o acesso às informações sobre o desenvolvimento histórico da ciência, "contribuindo para a mudança de postura dos professores em sala de aula" (LEITE, 2004, p. 10).

Em termos de cultura científica, a ciência apresenta centralidade em nossa sociedade. A qual, mesmo sofrendo ataques nos últimos anos com a propagação de correntes anticientíficas e negacionistas, principalmente por mídias sociais de fácil acesso à população (ALBUQUERQUE; QUINAN, 2019; NETO; ARAÚJO, 2019), tem sua importância afirmada para o desenvolvimento econômico, tecnológico, social e cultural de nos- 
sa comunidade (FONSECA; OLIVEIRA, 2015). Além disso, é fundamental ter em mente que, ao nos referimos à ciência e ao processo científico, estamos tratando dela como resultante dos processos de construção do conhecimento provenientes de atividades humanas exercidas pelos indivíduos que compõem nossa sociedade, dessa forma, incorporada em nossa cultura.

A concepção de cultura científica é abordada de diferentes maneiras por autores de influência no âmbito das políticas científicas e educacionais brasileiras (FONSECA; OLIVEIRA, 2015). Entre eles, Carlos Vogt apresenta uma concepção de cultura científica que inclui pautas e debates contemporâneos sobre a dinâmica entre ciência e sociedade, com ênfase na democratização e comunicação do saber. Vogt (2012) propõe, como forma de representação do movimento que ocorre entre a ciência e a cultura, o modelo intitulado "espiral da cultura científica", que coloca os Ensinos Fundamental e Médio - entre outros - como atores no ensino e formação de cientistas, por meio da democratização do conhecimento científico aos estudantes. Tendo dito que o livro didático é provavelmente o material mais utilizado nas redes públicas de ensino (JUNIOR; ANDRA$D E, 2015)$, deduz-se que é assim que a comunicação sobre a produção científica nesse ambiente ocorre em maior peso.

A partir deste cenário, tendo o livro didático como uma das principais ferramentas metodológicas empregadas no ensino de Ciências Biológicas, e ainda como um objeto facilitador da construção do conhecimento científico em âmbito escolar, torna-se importante compreender como a evolução biológica vem sendo trabalhada em termos de história da ciência e cultura científica. Deste modo, o objetivo deste artigo é analisar como os conteúdos de ensino sobre a Evolução Biológica vem sendo abordados quanto aos elementos pertencentes à história da ciência e da cultura científica presente em três livros para Ensino Médio, com maior distribuição no país, pelo Programa Nacional do Livro Didático - PNLD - de 2015.

\section{METODOLOGIA DA PESQUISA}

Em termos metodológicos, a pesquisa orientou-se pelo referencial teórico e metodológico da Análise de Conteúdo (BARDIN, 2016), a qual visa a obter "por procedimentos objetivos de descrição do conteúdo das mensagens, indicadores quantitativos (ou não) que permitam a inferência de conhecimentos relativos a condições de produção/recepção dessas mensagens" (BARDIN, 2016, p. 48). Dessa forma, a pesquisa foi realizada por meio da análise dos conteúdos de evolução biológica em livros didáticos avaliados, regulamentados e distribuídos às escolas públicas pelo PNLD de 2015, utilizados pelos estudantes do Ensino Médio.

Empregou-se como critério de seleção da amostra de análise os livros destinados ao 3o ano do Ensino Médio das três coleções com os maiores índices de distribuição no Brasil. Dessa forma, foram analisados os livros dispostos na Tabela a seguir: 
Tabela 1 - Lista dos livros didáticos selecionados a partir dos dados quantitativos de distribuição nas escolas em território nacional (PNLD, 2015, p. 8)

\begin{tabular}{ccc}
\hline $\begin{array}{c}\text { Código de } \\
\text { identificação } \\
\text { LD.1 }\end{array}$ & $\begin{array}{l}\text { Coleção - Volume (Autor) } \\
\text { Biologia Hoje - Volume 3. Genética - Evolução - Ecologia } \\
\text { (LINHARES, S. V.; GEWANDSZNAJDER, F.) }\end{array}$ & $\begin{array}{c}\text { Quantidade } \\
\text { por Coleção } \\
2.038 .216\end{array}$ \\
LD.2 & $\begin{array}{l}\text { Biologia em Contexto - Volume 2 - Adaptação e continuidade da } \\
\text { vida (AMABIS, J. M.; MARTHO, G. R.) }\end{array}$ & 1.329 .164 \\
LD.3 & $\begin{array}{l}\text { Biologia - Volume 3 - O Ser humano, Genética, Evolução. } \\
\text { (MENDONÇA, V.; LAURENCE, J.) }\end{array}$ & 984.159 \\
& \multicolumn{1}{c}{ Fonte: Os autores (2020). }
\end{tabular}

O acesso a estes materiais foi realizado a partir da solicitação às escolas estaduais que ofertam Ensino Médio no município de Curitiba, mediante esclarecimento do objetivo deste estudo. A partir do acesso aos livros, mobilizamos um aporte metodológico de cunho qualitativo, identificando, inicialmente, a organização e a distribuição do conteúdo de evolução biológica nas obras didáticas selecionadas. Foi observado se o conteúdo está apresentado em um único capítulo, em dois ou mais capítulos, ou até mesmo se existem menções ao tema durante a abordagem de outros assuntos, ao exemplo dos capítulos de ecologia e genética, tal qual proposto pelas DCNEMs (BRASIL, 2013).

Considerando o referencial metodológico e analítico (BARDIN, 2016), a ênfase da análise de conteúdo recaiu sobre duas categorias que foram observadas nos textos de evolução biológica que compõem os livros didáticos: a) cultura científica e b) história da ciência.

No que se refere à categoria cultura científica, utilizou-se como referencial Carlos Vogt (2006), segundo o qual essa expressão seria mais adequada do que alfabetização científica ou percepção/compreensão pública da ciência, pois a expressão cultura científica tem a vantagem de englobar tudo isso e conter, ainda, em seu campo de significações, a ideia de que o processo que envolve o desenvolvimento científico é um processo cultural em que existe a participação da cidadania no processo dinâmico da ciência e de suas relações com a sociedade. Dessa forma, foi observado, no corpo dos textos relacionados aos assuntos de evolução, se a ciência é apresentada de forma completa, imutável e aparentemente distante da sociedade ou se está sendo abordada como algo que faz parte de nossa cultura, ou seja, que a ciência é algo construído pela sociedade e está em processo contínuo de construção.

Para a análise dos conteúdos sobre a história da ciência, os trabalhos de Leite (2002), History of science in science education: Development and validation of a checklist for analysing the historical content of science textbooks, e A história da ciência nos livros didáticos de biologia do Ensino Médio: uma análise do conteúdo sobre o episódio da transformação bacteriana, de Gimeniz e Silva (2010), foram utilizados como base e inspiração.

O trabalho de Gimeniz e Silva (2010) é baseado no livro O Desenvolvimento do pensamento biológico: diversidade, evolução e herança, de Ernst Mayr (1998, p. 16-22), que apresenta diferentes tipos de histórias, classificadas como história lexicográfica, cronológica, biográfica, cultural e sociológica e história-problema. Nesta análise verifi- 
cou-se somente a presença da história-problema nos LDs. Este tipo de história caracteriza-se pelo estudo dos problemas e não pelos períodos (GIMENIZ; SILVA, 2010). Além do mais, a perspectiva deslindada pela história-problema possibilita estabelecer questionamentos fundamentais à pesquisa, e, assim, constituir interpretações críticas dos discursos e narrativas empregados nos LDs.

Em seu artigo History of science in science education: Development and validation of a checklist for analysing the historical content of science textbooks, Leite (2002) desenvolveu um instrumento para a análise do conteúdo histórico nos livros didáticos de ciências. Para isso, a autora elaborou diferentes dimensões, das quais foram utilizadas neste estudo: "Tipo e organização da informação histórica" e "Materiais utilizados" (Quadro 1). A contabilização de exemplos que se encaixem nas dimensões propostas foi realizada de forma quantitativa por dois pesquisadores de modo independente, pela qual o número de ocorrências foi somado em cada categoria. A fim de comparação entre um exemplo e outro utilizou-se abordagem qualitativa.

Quadro 1 - Dimensões e subdimensões para verificação de elementos da História da Ciência

\begin{tabular}{|c|c|}
\hline \multirow[b]{2}{*}{$\begin{array}{l}\text { Tipo e } \\
\text { organização } \\
\text { da } \\
\text { informação } \\
\text { histórica }\end{array}$} & $\begin{array}{l}\text { Cientistas } \\
\text { * vida dos cientistas: } \\
\text { - dados biográficos (pelo menos nome e data de nascimento) } \\
\text { - características pessoais (sentimentos, caráter, humor, etc.) } \\
\text { - episódios/anedotas (casados com..., decapitados por...) }\end{array}$ \\
\hline & $\begin{array}{l}\text { Evolução da Ciência } \\
\text { * tipo de evolução: } \\
\text { - menção a uma descoberta científica (uma descoberta ou ideia histórica é } \\
\text { mencionada) } \\
\text { - descrição da descoberta (acontecimento de uma determinada descoberta é } \\
\text { descrito) } \\
\text { * pessoas responsáveis } \\
\text { - cientistas individuais (um cientista é mostrado como a única pessoa } \\
\text { trabalhando para a descoberta) } \\
\text { - grupo de cientistas (dois ou mais cientistas conhecidos trabalharam juntos } \\
\text { para o mesmo propósito) } \\
\text { - comunidade científica (os cientistas da época seriam responsáveis pelo } \\
\text { acontecimento) }\end{array}$ \\
\hline \multirow{5}{*}{$\begin{array}{l}\text { Materiais } \\
\text { utilizados } \\
\text { para } \\
\text { apresentar a } \\
\text { informação } \\
\text { histórica }\end{array}$} & Fotos de cientistas \\
\hline & $\begin{array}{l}\text { Fotos de máquinas, equipamentos de laboratório, etc. (uma vez usados ou } \\
\text { descobertos por cientistas do passado) }\end{array}$ \\
\hline & $\begin{array}{l}\text { Fotos de máquinas, equipamentos de laboratório, etc. (uma vez usados ou } \\
\text { descobertos por cientistas do passado) }\end{array}$ \\
\hline & $\begin{array}{l}\text { Documentos/textos originais (produzidos/escritos pelos próprios cientistas; } \\
\text { podem ser traduzidos) }\end{array}$ \\
\hline & $\begin{array}{l}\text { Fontes secundárias (textos, modelos, desenhos de equipamentos não feitos } \\
\text { por cientistas/autores de livros didáticos) }\end{array}$ \\
\hline
\end{tabular}

Fonte: Adaptação de Leite (2002). 


\section{Evolução biológica: entre a cultura e a história da ciência em livros didáticos}

Com relação aos conteúdos analisados, pode-se afirmar que eles mostram características diferentes no que se refere à disposição dos assuntos e estrutura organizacional da obra. O LD.1 apresenta cinco capítulos sobre evolução dentro da terceira unidade do livro, sendo o penúltimo conteúdo a ser abordado; o LD.2 traz todo o conteúdo em três capítulos, disposto no volume 2 da coleção "Biologia em contexto", diferente dos outros dois livros, nos quais o conteúdo está inserido no volume 3 . Considerando que os volumes dos LDs estão relacionados com o ano em que serão trabalhados os conteúdos dentro de classe, a proposta dos autores de LD.2 sugere a abordagem do tema evolução biológica no segundo ano do Ensino Médio. Já o LD.3 é o único a apresentar um capítulo separado dos demais, de modo que o capítulo sobre evolução humana é o primeiro a ser apresentado, estando o restante do conteúdo de evolução nos últimos dois capítulos do livro.

De modo geral, os LDs, que são objeto de análise deste estudo, apresentaram os mesmos assuntos, variando na forma de abordagem em concordância com os principais pontos levantados pelas DCNEMs referentes à apresentação das diferentes escolas de pensamento e teorias proposta com seus respectivos períodos históricos e contextos sociais e culturais. Os demais resultados do estudo foram analisados com base em duas categorias complementares, a saber, a cultura científica e a história da ciência, condizentes com as principais características dos assuntos abordados sobre a Evolução Biológica nos livros didáticos.

\section{Cultura científica}

A abordagem da cultura científica nos livros didáticos analisados ocorreu, principalmente, por meio da utilização de temas transversais. O LD.1 e o LD.3 abordam, como tema transversal, o darwinismo social. O darwinismo social é uma corrente sociológica que teve início com as ideias de Herbert Spencer, e, de acordo com alguns autores, Darwin também estimulou tais ideias em seu livro "The Descent of Man", aplicando as leis da Teoria da Seleção Natural na vida e na sociedade humana (BOLSANELLO, 1996; WEIKART, 2009). Spencer foi o primeiro a proferir a emblemática frase "sobrevivência do mais apto", e "suas ideias sobre a evolução e o funcionamento das sociedades humanas foram mantidas em conjunto com suas fortes crenças individualistas e no laissez-faire (economia de livre-mercado sem restrições)" (HALLIDAY, 1971, p. 390; DENNIS, 1995, p. 244; WEIKART, 2009), rapidamente vinculadas por outras pessoas a ideias eugenistas e racistas no contexto do século 19 (BOLSANELLO, 1996; DENNIS, 1995). Tratar desse tema é de grande relevância, pois a discussão em sala de aula dessa "vertente obscura" da Teoria da Seleção Natural proporciona aos alunos uma formação que ultrapassa o caráter conteudista, auxiliando na formação cidadã dos alunos. De acordo com Almeida (2006), a abordagem de temas transversais nas aulas de ciências "podem contribuir para o estímulo à cidadania e para a melhoria da qualidade de vida do aluno no seu universo social e cultural" (ALMEIDA, 2006, p. 2).

Também são abordados pelo LD.1 e LD.2 outros temas transversais de cunho social, como a ideia de "raças humanas". Tal proposição é problematizada a partir do fato de que a cor da pele não é um parâmetro biológico para separação de raças, sendo 
"uma construção social que, muitas vezes, serve apenas de pretexto para o racismo" (LD.1, 2013, p. 150), assim como o darwinismo social, citado anteriormente. "A Antropologia Biológica e a Genética, atualmente, preferem trabalhar com o conceito de população" (SEYFERTH, 1995, p. 177). O fato, entretanto, de o conceito de raças ser rejeitado do ponto de vista biológico não anula que o conceito cultural de raça exista, inclusive é utilizado no Brasil como critério em políticas públicas (KAUFMANN, 2012). No campo escolar, ampliar essa discussão com os alunos é de suma importância, posto que os reflexos culturais do racismo também afetam crianças e adolescentes. Além disso, reconhece-se o potencial da escola em ser tanto um espaço de disseminação quanto um meio eficaz de prevenção e diminuição do preconceito (MENEZES, 2003).

No LD.2 e LD.3 é tratado sobre o Homem de Piltdown - um dos casos de fraude no campo científico -, mostrando que a "ciência é uma atividade humana e sofre influência do contexto sociocultural, de ambições de alguns cientistas e da mente criminosa de alguns fraudadores" (LD.3, 2013, p. 26). Para Dawkins (2009), essa fraude favoreceu aqueles que questionam a veracidade das teorias evolutivas e que a utilizam como pretexto para desacreditar os outros inúmeros fósseis verdadeiros que já foram encontrados.

Também no LD.3 é feita uma problematização acerca do exemplo do "Pescoço da girafa", utilizado para exemplificar a teoria de Lamarck e a da seleção natural de Darwin. Tal exemplificação, contudo, tem sido muito criticada pelos cientistas, que afirmam que a busca por alimento não seria a principal força de seleção atuante (LD.3, 2013). Tal temática mostra que é possível contestar e criticar a ciência, e que o conhecimento científico é perpassado por novas pesquisas engendradas a partir de discussões e debates.

Neste sentido, o conteúdo das obras estudadas corrobora o fato de a ciência estar em constante mudança, uma vez que é construída por uma sociedade e pelo método científico, também passíveis de mudanças. Ademais, vários personagens são citados como construtores da ciência, apresentando-a como resultado da colaboração em um processo laborioso com "erros e acertos". O que os diferia do restante era principalmente os questionamentos que faziam acerca do mundo que os cerca e o que faziam para responder tais questionamentos. Tornar a ciência algo tangível é essencial ao ensiná-la em sala de aula, tendo o LD um papel fundamental nesse processo.

\section{História da ciência: História Problema}

Na história dos problemas o cientista e o seu mundo conceitual são o foco. A construção desse tipo de história É norteada pelos seguintes questionamentos: "Quais foram os problemas científicos do seu tempo? Quais foram os instrumentos conceituais e técnicos de que dispunha na sua busca de uma solução? Quais foram os métodos que ele pôde utilizar? Que ideias predominantes na sua época orientaram a sua pesquisa e influenciaram as suas decisões?" (MAYR, 1998, p. 15).

Todos os livros apresentaram situações em que foram identificadas histórias-problema, com destaque ao papel de Lamarck à história da ciência evolutiva. As obras procuram reconhecer sua importância para o desenvolvimento das teorias evolutivas em trechos como: "é preciso situar Lamarck em sua época para compreender melhor seu valor [...] Sua tese provocou muitas discussões sobre a evolução e permitiu que o conhecimento desse fenômeno biológico se generalizasse" (LD.1, 2013, p. 111-112) e "Além 
disso, foi o primeiro a falar em evolução, numa época em que esse assunto não era aceito pela maioria da comunidade científica" (LD.3, 2013, p. 258). Com relação ao primeiro trecho, apesar de questionamentos que permeiam a temática de evolução existirem desde a Grécia Antiga e pensadores evolucionistas como Buffon, Maupertius e Diderot terem contribuído e influenciado Lamarck, a sua proposição de um mecanismo explicando que todos os organismos se desenvolveram a partir de ancestrais primitivos "foi uma ruptura profunda e radical" nas concepções existentes até então (MAYR, 1998). Quanto ao segundo trecho, a afirmação de que Lamarck foi o primeiro a "falar em evolução" é um equívoco, pois, como já mencionado, existiram ideias precursoras a Lamarck desde Anaximandro, no século 6 a.C. a Erasmus A. Darwin, avô de Charles Darwin, no final do século 18 (FREITAS, 2012).

Há a construção de uma história-problema nesse recorte, pois o mérito de Lamarck para a evolução foi significativo, posto que ele influenciou cientistas posteriores - como Darwin - e ajudou a romper com a ideia de espécies fixas. Observa-se que o debate sobre a transformação das formas de vida já ocorria na Europa por volta de 1800 (CORSI, 2005), mas o fixismo ainda era pensamento majoritário da comunidade científica. Cabe aqui mostrar que os autores dos livros didáticos analisados não mencionaram informações sobre outros personagens importantes para o rompimento de tais ideias.

Ademais, os autores de LD.1 justificam que "Lamarck não poderia ter explicado corretamente a transmissão das características hereditárias, pois na época nada se sabia sobre genes, DNA e os conhecimentos sobre herança eram incipientes" (LD.3, 2013, p. 258). Novamente é situado o contexto histórico no qual o cientista estava inserido, as limitações presentes em sua época e as possibilidades de contribuição do cientista para a História da Ciência. Não é possível afirmar, contudo, que Lamarck seria capaz de explicar corretamente o processo de transmissão de caracteres hereditários mesmo tendo disponíveis os conhecimentos necessários - da forma como o LD deixa a entender. Levando em consideração esses pontos, Darwin e Wallace também não proviam dos conhecimentos obtidos sobre hereditariedade a partir dos estudos de Mendel, mas elaboraram a Teoria da Seleção Natural (BIZZO; EL-HANI, 2009; STERN; ORGOGOZO, 2009).

Os autores favoreceram o processo de construção do pensamento científico e a quebra do estereótipo de que tudo que Lamarck sugeriu foi refutado, ao contrário de Darwin. Essa ideia é reforçada no LD.1, ao mencionar a rejeição às ideias de Darwin em sua época pela "falta de uma teoria que explicasse a origem e a transmissão das variações" (LD.1, 2013, p. 119). Esse fato não justifica a não aceitação de suas ideias, pois Darwin elaborou a "teoria da pangênese" para tentar explicar a hereditariedade (HOLTERHOFF, 2014). Além disso, era argumentado sobre outros fatores que Darwin não sabia explicar plenamente. Os autores então citam que: "Nas primeiras décadas do século $X X[. .$.$] houve uma síntese entre o darwinismo, as leis de Mendel e o conhecimento das$ mutações, que deu origem à teoria sintética da evolução" (LD.1, 2013, p. 119).

É possível notar, portanto, que, apesar da ideia de Darwin sobre seleção natural ser amplamente aceita hoje, anteriormente haviam discordâncias sobre ela e, devido à junção com conhecimentos posteriores, foi possível "preencher as lacunas" faltantes, problematizando a história científica apresentada. Ao falar sobre a teoria sintética da evolução, o LD.1 aborda que vários cientistas contribuíram para sua elaboração: "A teo- 
ria sintética foi desenvolvida a partir da década de 1930 com base em contribuições de cientistas de vários países [...]" (LD.1, 2013, p. 120). Ainda assim, o conteúdo poderia ter sido mais bem explorado pelos autores, pois foi um marco de suma importância por fornecer à teoria da seleção natural aquilo que lhe faltou por quase meio século: "uma fundação firme em uma teoria da hereditariedade bem testada" (RIDLEY, 2006, p. 38). Isso foi possível pela conciliação da teoria mendeliana da genética com a descrição biométrica da variação contínua em populações reais a partir de estudos independentes de vários autores, principalmente R. A. Fisher, que descreveu a frequência dos genes sob o efeito da seleção natural e se baseou em Mendel para explicar as diferenças entre os indivíduos transmitidas de forma hereditária, J. B. S. Haldane, que tratou da atuação da seleção natural em populações, e Sewall Wright, que contribuiu com estudo de interações gênicas na variabilidade de pequenas populações com alta endogamia (RIDLEY, 2006).

O LD.3, que foi o único a dar mais ênfase a história de Wallace, apresentou trechos relatando detalhes biográficos de sua vida, com sua viagem para a América do Sul: "Wallace começou a trabalhar com um jovem naturalista [...] convencido de que as espécies mudam ao longo do tempo, propôs [...] uma viagem ao Brasil para coletar animais [...] Na viagem de volta, o navio sofreu um incêndio e afundou em alto-mar" (LD.3, 2013, p. 267). Esse evento trágico que ocorreu com Wallace resultou na perda de material coletado e o prejudicou bastante, pois alguns autores afirmam que Darwin é mais reconhecido pela teoria da evolução em razão, além do status social, à enorme quantidade de material e anotações que ele possuía (LD.1, 2013).

Apesar de alguns pontos de discordância, Darwin e Wallace atingiram a concepção de seleção natural de forma independente e quase concomitante (BOWLER, 1989; CARMO; MARTINS, 2006). O maior reconhecimento dado a Darwin em virtude dessa teoria, está relacionado a vários fatores de acordo com Bowler (1989): o fato de Darwin ter elaborado sua versão 20 anos antes de Wallace e acelerado sua publicação somente ao receber cartas de Wallace contando a versão dele da teoria; apesar de a obra de Malthus ter influenciado os dois, eles seguiram caminhos diferentes; e também ao fato de Darwin, com a ajuda de seus amigos, Lyell e Hooker, ter divulgado o seu trabalho e o de Wallace na Linnean Society de Londres. Ao tratar sobre esta teoria, os autores dos LDs poderiam ter dado mais visibilidade a Wallace, tal como abordaram Darwin, ou abordado um pouco mais da problemática envolvendo os dois.

Apesar de abordar aspectos que se enquadram na história-problema, sua utilização ainda é muito discreta e poderia ser utilizada dentro de outras temáticas, como a teoria sintética da evolução, que só foi mais bem abordada no LD.1, e o modelo de Hardy-Weinberg, que nem foi citado no LD.2, e teve seu contexto histórico suprimido no LD.3. Há ainda muitas menções a cientistas, como poderá ser visualizado na próxima seção (conteúdo histórico), porém sua importância e como a descoberta científica foi construída, não são inseridas e a inclusão nominal de um personagem da ciência, sem um ponto de inflexão historiográfico, é apenas uma inclusão nominal (GIMENIZ; SILVA, 2010).

Sabe-se que abordar todos os "problemas da biologia e reconstituir o desenvolvimento da sua estrutura conceitual" por trás de uma descoberta é uma tarefa árdua devido à quantidade de material disponível com essas informações, afinal "nem o mais consciencioso historiador seria capaz de cobrir mesmo só um décimo de um por cem de 
todo esse material" (MAYR, 1998, p. 22). Esta situação intensifica-se, em especial, pelo aumento na produção científica nos últimos anos. Além disso, é preciso "lembrar que a história dos problemas não substitui a história cronológica. As duas abordagens são complementares" (MAYR, 1998, p. 16).

\section{HISTÓRIA DA CIÊNCIA: CONTEÚDO HISTÓRICO}

\section{Tipo e organização da informação histórica}

Foi possível perceber, durante a análise desta primeira dimensão (Tabela 2), que em todos os livros houve valores significativos da ocorrência de dados biográficos dentro da categoria "personagens". A maior parte dessas ocorrências, no entanto, trata apenas do nome do personagem, e as respectivas datas de nascimento e falecimento. Acerca de fatos considerados características pessoais - menção a sentimentos e humor -, foram poucas ocorrências destinadas aos textos que abordavam principalmente Darwin, por exemplo: "Ficou fascinado com a exuberância da floresta tropical, mas chocado com a escravidão" e "Para sua surpresa, Wallace tinha chegado às mesmas conclusões" (LD.1, 2013, p. 114-118).

Tabela 2 - Dimensão: Tipo e organização da informação histórica

\begin{tabular}{lccc}
\hline Tipo e organização da informação histórica & LD.1 & LD.2 & LD.3 \\
\hline Personagens (pensadores, filósofos, cientistas) & 31 & 36 & 21 \\
Dados biográficos & 3 & 6 & 1 \\
Características pessoais & 8 & 13 & 32 \\
Curiosidades & 42 & 55 & 54 \\
Total & & & \\
Evolução da ciência: Tipo de evolução & 21 & 30 & 21 \\
Simples menção & 11 & 12 & 10 \\
Descrição & 32 & 42 & 31 \\
Total & & & \\
Evolução da ciência: Responsável & 3 & 15 & 4 \\
Cientista individual & 7 & 16 & 7 \\
Grupo de cientistas & 3 & 4 & 4 \\
Comunidade científica & 13 & 35 & 15 \\
Total & & & \\
\hline
\end{tabular}

Fonte: Os autores (2020).

O LD.3 foi a obra com maior recorrência de informações (32 registros) classificadas dentro da categoria "curiosidades". Foram considerados casos de curiosidades as informações sobre realizações ou episódios ocorridos na vida dos personagens que não são fundamentais para a compreensão dos assuntos abordados, tal como a curiosidade sobre Wallace no trecho: "Aos 20 anos de idade, tornou-se professor de uma escola, onde ensinava português e matemática. No contato com a biblioteca da escola, interes- 
sou-se pelos livros de história natural" (LD.3, 2013, p. 267). Mesmo, todavia, que esses relatos de aspectos pessoais não sejam fundamentais para o entendimento do conteúdo, a presença dessas informações adicionais sobre a vida dos personagens promove uma "dimensão humana" (VIDAL; PORTO, 2012) que pode auxiliar no rompimento da visão do cientista como um personagem distante da realidade.

Para a subdimensão "Evolução da ciência" foram considerados teorias, conceitos, dispositivos tecnológicos, etc. que envolviam personagens da ciência. Os tipos de evolução que mais apareceram foram as "simples menções", ou seja, quando existe a menção a uma ideia científica, mas que ocorre de maneira superficial, sem maiores explicações. Diferentemente dos casos de "descrição", nos quais a ideia científica inclui maiores informações sobre a metodologia que foi utilizada, deu-se origem a esta ideia e maior detalhamento da teoria. Em comparação com os casos de descrição, as simples menções aparecem o dobro de vezes, ocasionando superficialidade acerca de alguns conteúdos, que poderiam ter sidos aprofundados, possibilitando ao estudante e leitor desses livros maiores reflexões sobre o processo de construção de uma teoria ou conhecimento científico. É possível observar um exemplo de simples menção no trecho: "Em 1864, o alemão naturalizado brasileiro Fritz Muller (1822-1897) concluiu que a existência de várias espécies parecidas de borboletas tóxicas reforça a proteção de todas contra predadores" (LD.2, 2013, p. 234). Já este trecho, presente no LD.2, é referente ao primeiro parágrafo do texto dedicado à Charles Darwin, o qual trata sobre sua expedição e, partir disso, aborda a elaboração da teoria da seleção natural, sendo considerada descrição:

O naturalista inglês Charles Robert Darwin (1809-1882) [...] Ao iniciar a viagem no Beagle, Darwin estava mais interessado em Geologia do que em Biologia. [...] Após diversas paradas [...], o Beagle seguiu para Galápagos [...] meses depois de voltar à Inglaterra, ao rever anotações e submeter o material coletado à análise de diversos especialistas [...] (LD.2, 2013, p. 210-211).

O ideal seria o aparecimento, em maior frequência, de elementos descritivos nas obras didáticas, pois "a simples menção não favorece reflexões a respeito do processo de construção do conhecimento científico, e em geral, serve apenas para apresentar, exemplificar ou reforçar conteúdos" (VIDAL; PORTO, 2012, p. 299). Entende-se, porém, que talvez não seja viável utilizar da descrição para todos os casos devido a densa quantidade de personagens citados ao longo dos capítulos que tratam sobre evolução.

Na maior parte dos casos, nas três obras, as ideias e teorias foram organizadas de forma sequencial, propiciando ao leitor a interpretação de que uma ideia surgiu em um período logo após o outro. As teorias evolutivas aparecem de forma linearizada, sendo apresentado primeiro o pensamento fixista, seguido das concepções de Lamarck sobre a mudança das espécies ao longo do tempo e, por último, as ideias de Darwin e Wallace. Em LD.1 e LD.2, entretanto, também apareceram textos que incluíram controvérsias, a retomada de ideias já expostas e menções a acontecimentos de diferentes períodos relacionados durante o desenvolvimento do conteúdo, permitindo a compreensão da dinâmica do processo de construção da ciência. Um exemplo dessa segunda forma de abordagem é o texto acerca da teoria sintética da evolução no LD.1, no qual os autores 
citam os estudos de Darwin e de Mendel, mencionando características dos estudos sobre hereditariedade realizados por Mendel que poderiam ter servido de embasamento para Darwin, que aceitava a teoria da pangênese (LD.1, 2013, p. 125). Esse segundo tipo de abordagem evita transpassar aos estudantes "uma visão de crescimento linear, puramente acumulativo, dos conhecimentos científicos", "ignorando as crises e as revoluções científicas" (CACHAPUZ et al., 2005, p. 52-58), posto que o caminho científico nunca será linear, havendo sempre teorias contrastantes (MAYR, 1998).

A respeito de quem "faz" a ciência, todos os livros apresentaram maior ocorrência para a categoria "grupo de cientistas". Este aspecto demonstra um fator positivo para a visualização da ciência como produto resultante de um grupo de pessoas trabalhando e construindo ideias em conjunto, o que reflete a realidade das produções científicas: "A teoria sintética foi desenvolvida a partir da década de $1930 \mathrm{com}$ base em contribuições de cientistas de vários países [...]" (LD.1, 2013, p. 125); "Um grupo de paleoantropólogos ingleses ficou particularmente feliz com tal descoberta [...]" (LD.3, 2013, p. 26).

A visão da produção de conhecimentos científicos, de forma individual, pode passar uma "ideia elitista da ciência e contribui a uma leitura descontextualizada, socialmente neutra da atividade científica (realizada por "gênios solitários")" (CACHAPUZ et al., 2005, p. 52), pois, mesmo cientistas que elaboram suas teorias sem participação direta de colegas, possuem influência de outros intelectuais e também influenciam outras pessoas posteriormente. Já o termo "comunidade científica" apareceu relacionado a pensamentos ou ideologias considerados consenso em determinados períodos históricos, a exemplo do fixismo antes das ideias de Lamarck, a teoria da seleção natural e a teoria sintética da evolução, que é, atualmente, um consenso dentro da comunidade científica.

O trabalho de Vidal e Porto (2012) utilizou a mesma metodologia proposta por Leite (2002) para analisar livros de química de Ensino Médio e obteve alguns resultados semelhantes, com exceção das características pessoais, das curiosidades e do grupos de cientistas, em que os livros de biologia analisados pelo presente estudo apresentaram maior quantidade de trechos que se enquadraram nesses quesitos. Não é possível apontar, com certeza, o motivo da diferença observada entre os trabalhos, mas outra análise com livros didáticos de química, também tomando a metodologia de Leite (2002) como base, demonstrou resultado bastante semelhante quanto à baixa quantidade dessas informações sobre os cientistas (SILVA; SANTOS; MENDONÇA, 2013).

\section{Materiais utilizados para apresentar a informação histórica}

Analisando a segunda dimensão, na qual foi verificada a presença de diferentes recursos a que os autores recorreram para inserir aspectos da história da ciência em seus textos (Tabela 3), foi possível perceber que o LD.1 apresentou maior diversidade e quantidade de recursos em comparação com os demais. 
Tabela 3 - Dimensão: Materiais utilizados para apresentar a informação histórica

\begin{tabular}{lccc}
\hline \multicolumn{1}{c}{ Materiais utilizados para apresentar a informação histórica } & LD.1 & LD.2 & LD.3 \\
Fotos de cientistas & 4 & 7 & 6 \\
Fotos de máquinas, equipamentos de laboratório, etc. & 1 & 1 & 1 \\
Documentos/textos originais & 5 & 4 & 3 \\
Experiências históricas & 4 & 0 & 0 \\
Fontes secundárias & 2 & 1 & 2 \\
Total & 16 & 13 & 12 \\
\hline
\end{tabular}

Fonte: Os autores (2020).

No recurso referente a "Imagens de cientistas" há um destaque para Lamarck, Darwin e Wallace, que sempre estão presentes em representações imagéticas. O LD.2 e o LD.3, entretanto, apresentaram fotos mais diversificadas como: Theodosius Dobzhansky, Thomas Malthus e Louis Leakey no LD.2 e James Hutton, Jane Goodall e Charles Lyell no LD.3. Em "Fotos de equipamentos, máquinas, etc.", inseriu-se a gravura que representava o Beagle H. M. S (barco utilizado por Darwin para sua expedição), observada em todos os livros analisados devido à sua importância no contexto histórico.

É interessante apontar aqui a baixa representatividade de mulheres quando se trata da produção científica. Somente a partir de 1970 os historiadores da Ciência passaram a atentar sobre a presença e credibilidade feminina neste meio (TABAK, 2002). Isso reflete no ambiente escolar, onde as crianças tendem a relacionar a profissão cientista como uma atividade masculina (CHAMBERS, 1983; MARTINS et al., 2014; MILLER et al., 2018; SOUZA et al., 2007), estereótipo que tende a ficar mais pronunciado com o passar dos anos escolares (MILLER, 2018). Nesse cenário, os LDs podem auxiliar na quebra desta preconcepção, apresentando mulheres como Etheldred Benett, Mary Anne Whitby, Rosalind Franklin e Barbara McClintock, além da já citada Jane Goodall, que contribuíram com seus estudos para o desenvolvimento de diversas áreas do conhecimento, como paleontologia, genética e geologia (CITELI, 2015; COLP JR., 1972; TORRENS et al., 2000).

O recurso sobre "Documentos ou textos originais" mostrou-se bem diversificado. No LD.1 há uma ilustração de Lamarck (LD.1, 2013, p. 112), citações de Darwin: "Essa preservação de variações favoráveis e rejeição de variações prejudiciais eu chamo de seleção natural" (LD.1, 2013, p. 117) e a famosa frase de Dobzhansky "Nada em biologia faz sentido a não ser à luz da evolução" (LD.1, p. 162). No LD.2 são mostradas páginas referentes a obras literárias de Darwin e Malthus, e também uma frase de Dobzhansky: "Interpretada à luz da evolução, a Biologia é, do ponto de vista intelectual, talvez a mais inspirada e satisfatória das ciências [...]" (LD.2, p. 208). Já o livro LD.3, apesar de utilizar menos este recurso, com apenas três ocorrências, mostrou citações de cientistas importantes e renomados, como Hardy e Weinberg (LD.3, 2013, p. 284). Somente o LD.1 apresentou como recurso relatos de experimentos, citando o experimento de Weismann. 
Como fontes secundárias, foram observadas nos três livros caricaturas de Darwin. No LD.1 era uma caricatura dele cercado dos animais que estudou, podendo ser considerada uma homenagem, porém no LD.2 e no LD.3 ele está representado como um macaco, pois sua teoria não foi bem aceita pela comunidade da época, principalmente por grupos religiosos, pois acreditavam que a teoria proposta por Darwin contrariava a Bíblia (RIDLEY, 2006) e ainda não é bem aceita por parte da população pelos mesmos motivos. Além disso, no LD.1 também há uma gravura mostrando a chegada do Beagle ao Rio de Janeiro, em 1832, em que é possível notar o contexto histórico da escravidão, que teria "horrorizado" Darwin (LD.1, 2013, p. 115). Essa gravura, por exemplo, poderia servir como estratégia didática como fonte de discussões críticas sobre os temas que as envolve, a exemplo da escravidão, saneamento, saúde, etc.

Ademais, o uso de representações iconográficas é muito utilizado no meio científico como recurso para a construção do pensamento científico, mas ainda pouco explorada na educação de ciências (CALLEGARIO et al., 2017, p. 838), apesar de ser considerada uma boa abordagem, por possibilitar que o aluno explore, conforme sua capacidade (FIÚZA; GUERRA, 2014) e com auxílio crucial e indispensável do professor (ZIMMERMANN; EVANGELISTA, 2004; CALLEGARIO et al., 2017), elementos que não estão presentes nas fontes primárias escritas, aprendendo, ao mesmo tempo, o conteúdo (FIÚZA; GUERRA, 2014).

\section{CONSIDERAÇÕES FINAIS}

A partir da análise das três obras didáticas abordadas neste estudo e tendo como base os parâmetros dos documentos oficiais do governo - DCNEM e BNCC -, atribui-se que os conteúdos privilegiados nos LDs atendem esses documentos. O que diferiu entre eles foi o enfoque, pelos autores, na abordagem das temáticas compreendidas pelos capítulos de evolução. O LD.1 apresentou maior prioridade no desenvolvimento do conteúdo referente às teorias evolutivas, quando comparado com o LD.2 e LD.3, que privilegiaram os processos evolutivos.

Ao que compete à cultura científica, se fez presente no discurso de todas as obras analisadas, porém localizadas nos textos dedicados a assuntos transversais, que, por serem considerados informações adicionais, podem não ser tratados em sala de aula. Dessa forma, sugere-se que a aproximação da cultura científica aos discentes aconteça no decorrer do texto com os conteúdos essenciais ao aprendizado.

Quanto à História da Ciência, apesar de haver no texto de todos os livros passagens com a inserção da história dos problemas, eles são escassos e estão focados, principalmente, em Lamarck. Também foi possível notar, por meio das dimensões analisadas, que, mesmo estando presentes situações que se caracterizam como história da ciência, estas não são sempre atendidas de forma satisfatória. As obras didáticas, além de apresentarem mais elementos pertencentes à história da ciência, poderiam explorar melhor sua abordagem. Uma possível ação, a fim de aprimorar este aspecto, é a incorporação de critérios - pelo edital de inscrição de livros didáticos no PNLD - que exijam a presença desses elementos, fazendo com que a comissão técnica se atente a isso. 
Como implicação desta análise para a área do ensino de ciências e biologia, pode-se apontar a crítica sobre a formulação dos livros didáticos brasileiros, que poderiam incorporar mais elementos de História da Ciência e cultura científica no conteúdo destinado ao ensino do tema evolução biológica, posto que é um material pedagógico de suma importância, utilizado tanto pelos estudantes quanto pelos professores da educação básica. O ensino desta temática, a partir dos aspectos destacados neste estudo, facilitam significativamente a assimilação acerca do papel da ciência no nosso cotidiano. Ademais, assume-se que, como um dos principais temas que envolvem os conhecimentos da biologia, há um potencial inerente no seu aprendizado para a compreensão da construção do processo e método científico, contribuindo, assim, para combater teorias pseudocientíficas e a aversão à ciência, infelizmente cada vez mais expressivas em nossa sociedade. Tendo, portanto, como base os três livros analisados neste estudo e que eles foram os mais distribuídos nas escolas públicas no PNLD de 2015, sugere-se que, para obtenção de uma educação crítica, contextualizada histórica, social e culturalmente, que atenda às diretrizes curriculares propostas pelo MEC, devam ser utilizados, além dos livros didáticos, outros materiais pedagógicos para auxiliar nesse processo, como livros paradidáticos da área de evolução biológica, jogos colaborativos e textos ou vídeos de apoio já existentes ou elaborados pelo docente com base na literatura pertinente.

\section{REFERÊNCIAS}

ALBUQUERQUE, A.; QUINAN, R. Crise epistemológica e teorias da conspiração: o discurso anti-ciência do canal "Professor Terra Plana". Revista Mídia e Cotidiano, v. 13, n. 3, p. 83-104. 2019. DOI: https://doi. org/10.22409/rmc.v13i3.38088

ALMEIDA, A. V.; DA ROCHA FALCÃO, J. T. As teorias de Lamarck e Darwin nos livros didáticos de Biologia no Brasil. Ciência \& Educação, Bauru, v. 16, n. 3, p. 649-665, 2010. DOI: https://doi.org/10.1590/S151673132010000300010

ALMEIDA, T. J. B. Abordagem dos temas transversais nas aulas de ciências do Ensino Fundamental, no distrito de Arembepe, município de Camaçari-BA. Candombá - Revista Virtual, v. 2, n. 1, p. 1-13, 2006.

AMABIS, J. M.; MARTHO, G. R. Biologia em contexto - volume 2. 1. ed. São Paulo: Moderna, 2013.

BARDIN, L. Análise de conteúdo. 3ạ reimp. São Paulo: Edições 70, 2016.

BATISTA, I. D. L. Reconstruções histórico-filosóficas e a pesquisa em educação científica e matemática. In: NARDI, R. (org.). A pesquisa em ensino de ciências no Brasil: alguns recortes. São Paulo: Escrituras Editora, 2007. p. 257-272.

BIZZO, N.; EL-HANI, C. N. Darwin and Mendel: evolution and genetics. Journal of Biological Education, v. 43, n. 3, p. 108-114, 2009. DOI: https://doi.org/10.1080/00219266.2009.9656164

BOLSANELLO, M. A. Darwinismo social, eugenia e racismo "científico": sua repercussão na sociedade e na educação brasileira. Educar em Revista, v. 12, p. 153-165, 1996. DOI: http://dx.doi.org/10.1590/01044060.166

BORGERDING, L. A. et al. Student Teachers' Approaches to Teaching Biological Evolution. Journal of Science Teacher Education, v. 26, n. 4, p. 371-392, 2015.

BOWLER, P. J. Evolution: the history of an idea. California: University of California Press, 1989.

BRASIL. Ministério da Educação. Diretrizes Curriculares Nacionais da Educação Básica. Brasília: MEC, 2013. BRASIL. Ministério da Educação. Base Nacional Comum Curricular: Ensino Médio. Brasília: MEC, 2018. CACHAPUZ, A. et al. A necessária renovação do ensino das ciências. São Paulo: Cortez Editora, 2005.

CALLEGARIO, L. J. et al. As imagens científicas como estratégia para a integração da história da ciência no ensino de ciências. Revista Brasileira de Pesquisa em Educação em Ciências, v. 17, n. 3, p. 835-852, 2017. DOI: https://doi.org/10.28976/1984-2686rbpec2017173835

CAPONI, G. Contra la lectura adaptacionista de Lamarck. In: ROSAS LOPEZ, A. Filosofía, darwinismo y evolución. Bogotá: Universidad Nacional de Colombia, 2007. p. 3-18. 
CARMO, V. A.; MARTINS, L. A. C. P. Charles Darwin, Alfred Russel Wallace e a seleção natural: um estudo comparativo. Filosofia e História da Biologia, v. 1, n. 1, p. 335-350, 2006.

CITELI, M. T. Mulheres nas ciências: mapeando campos de estudo. Cadernos Pagu, v. 15, p. 39-75, 2015.

COLP JR., R. Charles Darwin and Mrs. Whitby. Bulletin of the New York Academy of Medicine, v. 48, n. 6, p. 870, 1972.

CORSI, P. Before Darwin: Transformist concepts in European natural history. Journal of the History of Biology, v. 38, n. 1, p. 67-83, 2005. DOI: https://doi.org/10.1007/s10739-004-6510-5

CHAMBERS, D. W. Stereotypic images of the scientist: The Draw-a-Scientist Test. Science Education, v. 67, n. 2, p. 255-265, 1983. DOI: https://doi.org/10.1002/sce.3730670213

DAWKINS, R. O maior espetáculo da terra: as evidências da evolução. Tradução Laura Teixeira Motta. São Paulo: Companhia das Letras, 2009.

DENNIS, R. M. Social Darwinism, scientific racism, and the metaphysics of race. Journal of Negro Education, p. 243-252, 1995. DOI: https://doi.org/10.2307/2967206

DOBZHANSKY, T. Nothing in biology makes sense except in the light of evolution. The American Biology Teacher, v. 35, n. 3, p. 125-129. 1973. DOI: https://doi.org/10.2307/4444260.

FIÚZA, L.; GUERRA, A. Controvérsias históricas em torno a ideia de natureza: atividades com imagens. Ensaio Pesquisa em Educação em Ciências, Belo Horizonte, v. 16, n. 2, p. 125-146, 2014. DOI: https://doi. org/10.1590/1983-21172014160207

FREITAS, L. A teoria evolutiva de Darwin e o contexto histórico. Revista Bioikos, v. 12, n. 1, 2012.

FONSECA, M. A.; OLIVEIRA, B. J. Variações sobre a "cultura científica" em quatro autores brasileiros. História, Ciências, Saúde, Manguinhos, v. 22, n. 2, p. 445-459, 2015. DOI: https://doi.org/10.1590/S010459702015005000011

FUTUYMA, D. J. Biologia Evolutiva. 3. ed. Ribeirão Preto: Editora Funpec, 2009.

GIMENIZ, S. R.; SILVA, M. R. A história da ciência nos livros didáticos de biologia do Ensino Médio: uma análise do conteúdo sobre o episódio da transformação bacteriana. Alexandria: Revista de Educação em Ciência e Tecnologia, v. 3, n. 2, p. 59-78, 2010.

GOEDERT, L.; DELIZOICOV, N. C.; ROSA, V. L. A formação de professores de Biologia e a prática docente - o ensino de evolução. ENCONTRO NACIONAL DE PESQUISA EM EDUCAÇÃO EM CIÊNCIAS (ENPEC), 4., 2003. Bauru. Atas [...]. Bauru, SP: Abrapec, 2003.

GAUTHIER, P. Does Weismann's Experiment Constitute a Refutation of the Lamarckian Hypothesis? Bios, v. 61, n. 1, p. 6-8, 1990.

HALLIDAY, R. J. Social Darwinism: a definition. Victorian Studies, v. 14, n. 4, p. 389-405, 1971.

HOLTERHOFF, K. The history and reception of Charles Darwin's hypothesis of pangenesis. Journal of the History of Biology, v. 47, n. 4, p. 661-695, 2014.

JUNIOR, F. P. C.; ANDRADE, M. A. B. S. A relação entre os conhecimentos presentes na literatura científica e nos livros didáticos de biologia sobre evolução biológica. Revista Brasileira de Ensino de Ciência e Tecnologia, v. 8, n. 3, 2015.

KAUFMANN, R. F. M. Ações afirmativas à brasileira: necessidade ou mito? Unijus, 117, 2012.

LINHARES, S. V.; GEWANDSNADJER, F. Biologia hoje. 2. ed. São Paulo: Ática, 2013. Vol. 3.

LEITE, L. History of science in science education: Development and validation of a checklist for analysing the historical content of science textbooks. Science \& Education, v. 11, n. 4, p. 333-359, 2002. DOI: https://doi.org/10.1023/A:1016063432662

LEITE, R. C. M. A produção coletiva do conhecimento científico: um exemplo no ensino de genética. 2004. Tese (Doutorado em Educação) - UFSC/CED, Programa de Pós-Graduação em Educação, Florianópolis, 2004.

MARTINS, C. et al. A figura do cientista na visão de estudantes do Ensino Fundamental. Revista de Ensino de Biologia da Associação Brasileira de Ensino de Biologia, v. 7, p. 1.068-1.079, 2014.

MARTINS, I. Analisando livros didáticos na perspectiva dos Estudos do Discurso: compartilhando reflexões e sugerindo uma agenda para a pesquisa. Pro-Posições, v. 17, n. 1, p. 117-136, 2016.

MARTINS, R. A. Introdução: a história das ciências e seus usos na educação. In: SILVA, C. C. Estudos de história e filosofia das ciências: subsídios para aplicação no ensino. São Paulo: Editora Livraria da Física, 2006. p. 17-30.

MARTINS, R. D. A. August Weismann, Charles Brown-Séquard e a controvérsia sobre herança de caracteres adquiridos no final do século XIX. Filosofia e História da Biologia, v. 5, n. 1, p. 141-176, 2010. 
MATTHEWS, M. S. História, filosofia e ensino de ciências: a tendência atual de reaproximação. Caderno Brasileiro de Ensino de Física, v. 12, n. 3, p. 164-214, 1995. DOI: https://doi.org/10.5007/\%x

MAYR, E. O desenvolvimento do pensamento biológico: diversidade, evolução e herança. Brasília: Editora UnB, 1998.

MENEZES, W. O preconceito racial e suas repercussões na instituição escola. Cadernos de Estudos Sociais, v. 19, n. 1, 2003.

MENDONÇA, V. L.; LAURENCE, J. Biologia - volume 3. 2. ed. São Paulo: AJS, 2013.

MILLER, D. I. et al. The development of children's gender-science stereotypes: A meta-analysis of 5 decades of US Draw-a-Scientist studies. Child development, v. 89, n. 6, p. 1.943-1.955, 2018. DOI: https:// doi.org/10.1111/cdev.13039

MEC. Ministério da Educação e Cultura. Programa Nacional do Livro Didático: edital de convocação para o processo de inscrição e avaliação de obras didáticas para o PNLD 2015. Portal do MEC, 2013.

NETO, L. F. P.; ARAÚJO, S. A divulgação científica na internet como garantidor do direito fundamental à educação nas eras da anticiência e da cibercultura. Revista de Estudos Jurídicos do UNI-RN, v. 3, p. 27-27, 2019.

PEREIRA, H. M. R.; EL-HANI, C. N. A dinâmica discursiva no contexto do ensino da evolução biológica. ENCONTRO NACIONAL DE PESQUISA EM EDUCAÇÃO EM CIÊNCIAS, 8., 2011. Campinas. Atas [...]. Campinas, SP: Abrapec, 2011.

PIOLLI, A.; DIAS, S. Escolas não dão destaque à evolução biológica. ComCiência, v. 56. 2004.

PNLD. Programa Nacional do Livro e do Material Didático. Coleções mais distribuídas por componente curricular. Brasília: Fundo Nacional de Desenvolvimento da Educação, 2015. p. 8.

RIDLEY, M. Evolução. 3. ed. Porto Alegre: Artmed Editora, 2006.

SEYFERTH, G. A invenção da raça e o poder discricionário dos estereótipos. Anuário Antropológico, v. 18, n. 1, p. 175-203, 1995.

SILVA, C. M.; SANTOS, C. G.; MENDONÇA, P. C. C. Análise da história da ciência em livros didáticos de química aprovados no PNLD 2012. ENCONTRO NACIONAL DE PESQUISA EM EDUCAÇÃO EM CIÊNCIAS ENPEC, 9., 2013. Águas de Lindoia. Atas [...]. Águas de Lindoia, SP. 2013.

SINATRA, G. M.; BREM, S. K.; EVANS, E. M. Changing Minds? Implications of Conceptual Change for Teaching and Learning about Biological Evolution. Evolution: Education and Outreach, v. 1, n. 2, p. 189-195, 2008. DOI: https://doi.org/10.1007/s12052-008-0037-8.

SOUZA, R. et al. Concepções dos estudantes sobre a ciência, os cientistas e o método científico: uma abordagem histórico-crítica como base para uma proposta de intervenção visando a ressignificação destes conceitos. XVII Simpósio Nacional de Ensino de Física. Anais... São Luís, Maranhão, v. 29, 2007.

STERN, D. L.; ORGOGOZO, V. Is genetic evolution predictable? Science, v. 323, n. 5.915, p. 746-751, 2009. DOI: https://doi.org/10.1126/science.1158997

TABAK, F. Estudos substantivos sobre mulher e ciências no Brasil. In: COSTA, A. A.; SARDENBERG, C. M. B. (org.). Feminismo, ciência e tecnologia. Rede Feminista Norte e Nordeste de Estudos e Pesquisas sobre Mulher e Relações de Gênero - Redor - e Núcleo de Estudos Interdisciplinas sobre a Mulher - Neim. Universidade Federal da Bahia - FFCH/UFA: Salvador, BA, 2002. p. 39-49.

TIDON, R.; LEWONTIN, R. C. Teaching evolutionary biology. Genetics and molecular biology, v. 27, n. 1, 124-131, 2004. DOI: https://doi.org/10.1590/S1415-47572004000100021

TORRENS, H. S. et al. Etheldred Benett of Wiltshire, England, the First Lady Geologist: Her Fossil Collection in the Academy of Natural Sciences of Philadelphia, and the Rediscovery of "Lost" Specimens of Jurassic Trigoniidae (Mollusca: Bivalvia) with Their Soft Anatomy Preserved. Proceedings of the Academy of Natural Sciences of Philadelphia, p. 59-123, 2000.

VASCONCELO, S. D.; SOUTO, E. O livro didático de ciências no Ensino Fundamental proposta de critérios para análise do conteúdo zoológico. Ciência \& Educação, v. 9, n. 1, p. 93-104, 2003. DOI: https://doi. org/10.1590/S1516-73132003000100008

VIDAL, P. H. O.; PORTO, P. A. A história da ciência nos livros didáticos de química do PNLEM 2007. Ciência \& Educação, Bauru, v. 18, n. 2, p. 291-308, 2012. DOI: https://doi.org/10.1590/S1516-73132012000200004 VOGT, C. Cultura científica: desafios. São Paulo: Edusp, 2006.

VOGT, C. The spiral of scientific culture and cultural well-being: Brazil and Ibero-America. Public Understanding of Science, v. 21, n. 1, p. 4-16, 2012. DOI: https://doi.org/10.1177/0963662511420410 
WEIKART, R. Was Darwin or Spencer the father of laissez-faire social Darwinism? Journal of Economic Behavior \& Organization, v. 71, n. 1, p. 20-28, 2009. DOI: https://doi.org/10.1016/j.jebo.2007.06.011

ZIMMERMANN, E.; EVANGELISTA, P. C. Q. Leitura e interpretação de imagens de Física no Ensino Fundamental. In: IX Encontro Nacional de Pesquisa em Ensino de Física. Jaboticatubas, MG: Sociedade Brasileira de Física, 2004. 